ARTICLE

\title{
IL-4R $\alpha$ expression by airway epithelium and smooth muscle accounts for nearly all airway hyperresponsiveness in murine allergic airway disease
}

\author{
Christopher G. McKnight ${ }^{1,2}$, Crystal Potter ${ }^{2}$ and Fred D. Finkelman iD $^{2,3}$
}

\begin{abstract}
Airway hyperresponsiveness (AHR) often defines asthma. Murine allergic airway disease (AAD), like human eosinophilic asthma, is characterized by AHR, eosinophilia, goblet cell metaplasia (GCM), smooth muscle hypercontractility, and increased production of IL4 and IL-13-cytokines that induce these characteristics by binding to the IL-4Ra chain. We evaluated the epithelial and smooth muscle IL-4Ra-dependent contributions to AHR of BALB/c mice that possessed 0-2 functional IL-4Ra alleles and had airway disease induced by house dust mite extract (HDM) or exogenous IL-13. Two functional IL-4Ra alleles were required for maximal AHR, while only one functional allele was required for maximal GCM and systemic IL-4/IL-13 levels. Deletion of IL-4Ra from both smooth muscle and epithelial cells inhibited AHR $>83 \%$ in mice with two functional IL-4Ra alleles. In mice with one functional IL-4Ra allele, selective epithelial cell IL-4Ra deletion maximally inhibited AHR, while selective smooth muscle IL-4Ra deletion decreased IL-13-induced, but not HDM-induced, AHR. Less IL-4Ra signaling is required to maximize the epithelial cell contribution to AHR compared to the smooth muscle contribution to AHR. In addition, epithelial cell responses to IL-4/IL-13 can increase the IL-4Ra-dependent smooth muscle contribution to AHR. These findings carry increasing relevance as IL-4Ra-targeted therapy is administered to human asthmatics.
\end{abstract}

Mucosal Immunology (2020) 13:283-292; https://doi.org/10.1038/s41385-019-0232-7

\section{INTRODUCTION}

Airway hyperresponsiveness (AHR) to methacholine can define asthma when symptoms are consistent with episodic bronchoconstriction. ${ }^{1}$ Although murine allergic airway disease (AAD) is an imperfect model of human asthma, mice reliably demonstrate AHR upon cholinergic stimulation when their pulmonary tissues have been pathologically modified by inflammation. ${ }^{2}$ While several cytokines are associated with the manifestation of AAD, interleukin (IL)-4 and IL-13 are considered the most central for several reasons. ${ }^{3-5}$ When binding the heterodimer of IL-4Ra and the common $\gamma$ chain for type I cytokine receptors on lymphocytes, IL-4 provides for the differentiation of naive $T$ cells into $T$ helper type 2 (Th2) cells, maintenance of the Th2 response through autocrine effects, and IgE class switching by $B$ cells. ${ }^{6,7}$ When binding the heterodimer of IL-4Ra and IL-13Ra1 on structural cells of the lung, IL-13 and IL-4 induce chemokine secretion, goblet cell metaplasia (GCM), myofibroblast metaplasia, and smooth muscle hyperresponsiveness. ${ }^{3,8-13}$ In addition, IL-4Ra is required for AAD in that IL-4Ra-deficient mice do not develop allergic disease and, when reconstituted with IL-4Ra-competent bone marrow, do not demonstrate AHR despite the presence of allergic inflammation. ${ }^{10,14}$

Because allergic AHR depends on IL-4Ra so critically, IL-4Radirected studies have proven useful in dissecting the mechanism of AHR in experimental asthma. Several mouse studies have evaluated the importance of IL-4Ra signaling in airway structural cell types. While these studies have shown that expression and stimulation of IL-4Ra on epithelial cells (ECs) or smooth muscle cells (SMCs) can induce AHR, selective deletion of IL-4Ra from ECs or SMCs fails to fully suppress AHR. ${ }^{10-14}$ These observations leave several questions unanswered, particularly: What is the relative importance of IL-4Ra signaling in ECs and SMCs in AAD? How do ECs and SMCs cooperate to produce AHR through IL-4Ra signaling? Do other airway structural cell types contribute substantially to AHR in AAD? Do the contributions to AHR by structural cell types depend on the method of disease induction?

We have now addressed these uncertainties using mice that selectively lack IL-4Ra in airway ECs, SMCs, or both cell types using a reductionistic model of asthma in which $A A D$ is induced by recombinant mouse IL-13 delivered intratracheally (i.t.) and an active immunization model of asthma in which AAD is induced by house dust mite (HDM) delivered i.t. Our results demonstrate that IL-4Ra expression by ECs and IL-4Ra expression by SMCs are individually required for full manifestation of AHR in both models of disease. However, the contribution of ECs to AHR was larger than the contribution made by SMCs, sometimes by a striking degree in a manner that depended upon genomic IL-4Ra copy number. When IL-4Ra expression by SMC was impaired, the contribution made by SMCs to AHR depended upon IL-4Ra expression by ECs. Ultimately, we found that the expression of IL4 Ra by both ECs and SMCs accounted for the great majority of AHR whether disease was induced by exogenous IL-13 or HDM.

\footnotetext{
${ }^{1}$ Department of Medicine, Cincinnati Veteran's Administration Medical Center, Cincinnati, OH 45220, USA; ${ }^{2}$ Department of Internal Medicine, University of Cincinnati College of Medicine, Cincinnati, OH 45267, USA and ${ }^{3}$ Division of Immunobiology, Cincinnati Children's Hospital Medical Center, Cincinnati 45229, USA Correspondence: Fred D. Finkelman (finkelfd@ucmail.uc.edu)
}

Received: 30 May 2019 Revised: 4 November 2019 Accepted: 5 November 2019

Published online: 19 November 2019 


\section{RESULTS}

To increase efficiency of Cre-mediated disruption of IL-4Ra in targeted cell types, we initially used IL-4Ra ${ }^{\text {flox/- }}$ mice that carried CC10-Cre, SMP8-Cre, both, or neither of these constructs. These mice were inoculated daily i.t. with $3 \mu \mathrm{g}$ of IL-13 on 7 consecutive days. Severe AHR was induced in mice lacking Cre-constructs, and AHR was substantially attenuated in mice that had little or no expression of IL-4Ra by ECs or by SMCs, as driven by the CC10-Cre or SMP8-Cre constructs, respectively. When IL-4Ra expression was reduced in both these cell types, AHR was reduced further but not extinguished (Fig. 1a). Such treatment with IL-13 induced a modest pulmonary eosinophilia that did not consistently depend upon IL-4Ra expression by SMCs or ECs (Fig. 1b). IL-13 induced strong GCM that was impeded by the CC10-Cre construct (Fig. 1c). Because Cre-mediated gene targeting is often known to be incomplete, we compared the range and distribution of residual IL-13-induced GCM in the CC10-Cre ${ }^{+/-}$and CC10-Cre ${ }^{+/-}$SMP8-
$\mathrm{Cre}^{+/-}$groups (Fig. 1d). Finding their residual GCM to be very similar, we compared the AHR of these groups when there was good prevention of GCM (Fig. 1g). The value of this comparison is validated by the lack of a statistically significant difference in eosinophilia between the subgroups that demonstrated high or low GCM with either genotype (Fig. 1e, f). Figure $1 \mathrm{~g}$ demonstrates that AHR was still present in the $\mathrm{CC} 10-\mathrm{Cre}^{+/-}$SMP8-Cre ${ }^{+/-}$mice treated with IL-13 even when GCs were very well eliminated, but, importantly, the AHR of $\mathrm{CC} 10-\mathrm{Cre}^{+/-}$SMP8-Cre ${ }^{+/-}$mice was indistinguishable from $\mathrm{CC} 10-\mathrm{Cre}^{+/-}$mice. This demonstrates that the SMC contribution to AHR in this model depends upon coexpression of IL-4Ra by ECs. Because the SMC contribution to AHR was not apparent when mice carried the CC10-Cre construct and had $<2 \%$ airway GCs, we wanted to evaluate whether the CC10Cre construct was impairing SMC function through its genomic insertion or non-specific effects of Cre. CC10-Cre ${ }^{+/-}$SMP8-Cre ${ }^{+/-}$ $\mathrm{IL}-4 \mathrm{Ra}^{-1-}$ mice were bred to wild-type (WT) mice to produce mice a
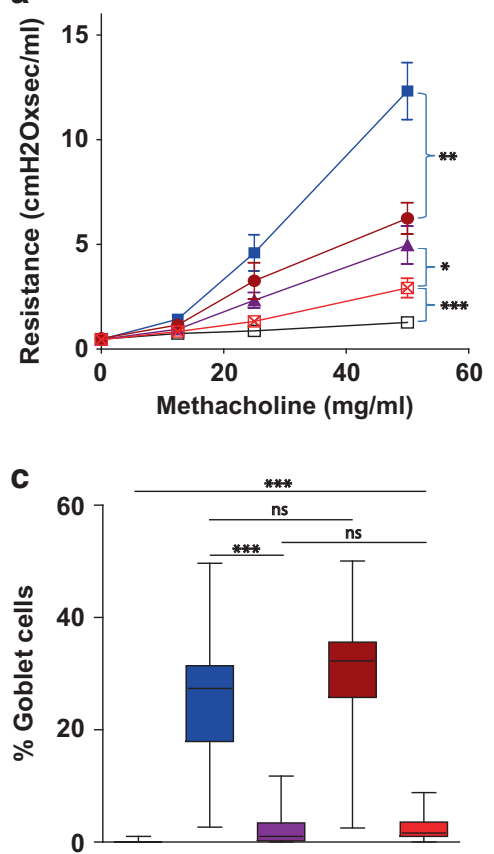

f

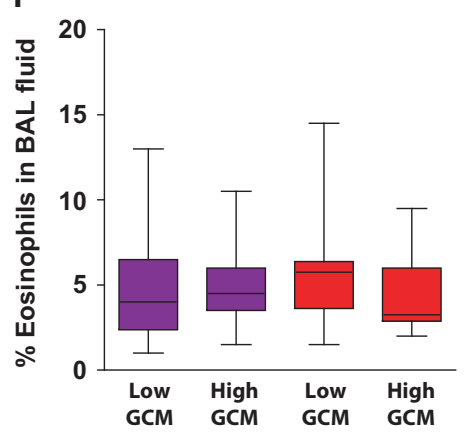

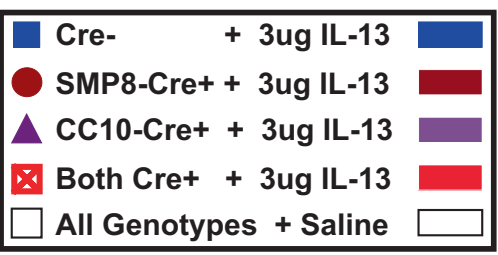

d

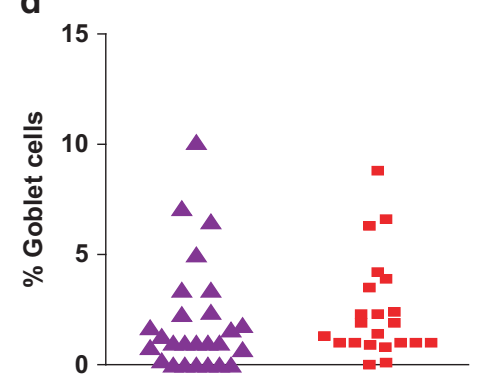

$\mathbf{g}$

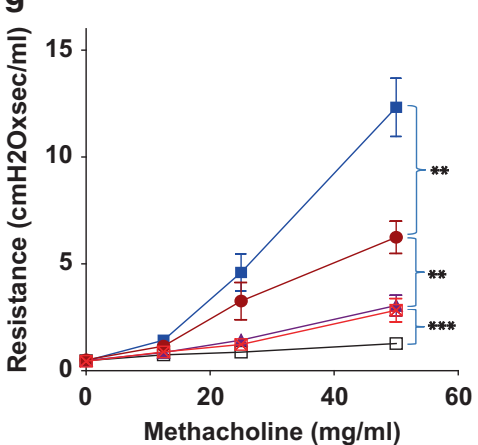

b

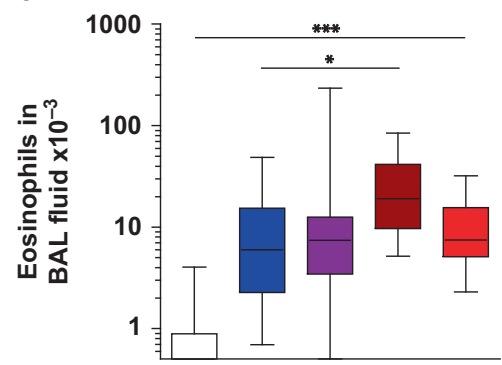

e

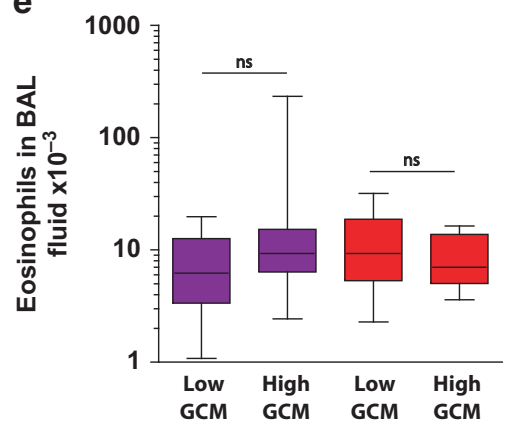

Fig. 1 IL-4R $\alpha$-expression by epithelial cells (ECs) and smooth muscle cells (SMCs) is required in IL-4Ro flox/- mice for maximal airway hyperresponsiveness (AHR) induced by exogenous IL-13. IL-4R $\alpha^{\text {flox } /-}$ mice were treated i.t. with $3 \mu \mathrm{g}$ of IL-13 daily for 7 days. a Invasive measurement of AHR. b Absolute eosinophil count of BAL fluid. c Quantitation of goblet cell metaplasia (GCM). d Distribution of residual GCM in club cell $10 \mathrm{kDa}$ protein-Cre ${ }^{+}\left(\mathrm{CC} 10-\mathrm{Cre}^{+}\right)$mice and CC10-Cre ${ }^{+} \alpha-$ smooth muscle actin-Cre $^{+}\left(\mathrm{SMP}_{-}-\mathrm{Cre}^{+}\right)$mice. e Absolute eosinophil count of BAL fluid in $\mathrm{CC} 10-\mathrm{Cre}^{+}$and CC10-Cre ${ }^{+} \mathrm{SMP} 8-\mathrm{Cre}^{+}$mice that had high or low residual GCM. f Percentage of eosinophils in BAL fluid in CC10$\mathrm{Cre}^{+}$mice and CC10-Cre ${ }^{+}$SMP8-Cre ${ }^{+}$that had high or low residual GCM. g AHR when CC10-Cre ${ }^{+}$and CC10-Cre ${ }^{+} \mathrm{SMP}_{-}-\mathrm{Cre}{ }^{+}$mice that had high residual GCM were excluded. The results represent 12 pooled experiments with a-d showing 17, 14, 26, 22, and 47 mice for the groups $\mathrm{Cre}^{-}+\mathrm{IL}-13$, SMP8-Cre + IL-13, CC10-Cre + IL-13, both Cre ${ }^{+}+\mathrm{IL}-13$, and all genotypes + saline, respectively. $\mathrm{g}$ represents 14 and 12 mice for the groups CC10-Cre ${ }^{+}+\mathrm{IL}-13$ and both $\mathrm{Cre}^{+}+\mathrm{IL}-13$, respectively. NS not significant; ${ }^{*} p<0.05 ;{ }^{* *} p<0.01 ;{ }^{* * *} p<0.001$. 
that were IL-4Ra ${ }^{+/-}$and carried one, both, or neither of the Cre constructs. Such mice would carry the putative damaging effects of the Cre construct but the recombinase activity of Cre would not alter the native IL-4Ra allele. Administering $3 \mu \mathrm{g}$ of the second lot of IL-13 i.t. daily 7 times to these mice generated AHR that was not impeded by either of the Cre constructs (Fig. E4). Thus Cre effects resulted from deletion of floxed IL-4Ra; not from a direct toxic effect.

Because a substantial percentage of $\mathrm{CC}_{10}-\mathrm{Cre}^{+}$mice demonstrated excessive residual GCM upon disease induction, we sought a strain with higher efficiency for deleting IL-4Ra from epithelium. The CC10-Cre strain originally made by Dr. Brigid Hogan was generated by pseudorandom insertion of the CC10-Cre construct that very likely occurred at multiple sites within the genome. Such mice have been maintained on a non-BALB/c background by several laboratories, and we backcrossed the CC10-Cre strain that we received from Steven Shapiro onto the BALB/c background using a traditional approach. The same construct was independently backcrossed onto the BALB/c background by Andrew Lindsley's laboratory using Taconic's Speed Congenic system; the resulting strain was labeled CCSP-Cre. Because regions of the genome vary substantially with regard to transcription accessibility and because the process of backcrossing might have selected different insertion sites of the CC10-Cre construct, we thought it worthwhile to assess the CCSP-Cre strain's efficacy for deletion of IL-4Ra. IL-4Ra ${ }^{\text {flox/- }}$ mice that did, or did not, carry
CCSP-Cre were treated with IL-13 or saline. AHR and GCM were substantially reduced, but not extinguished, in CCSP-Cre ${ }^{+/-}$mice (Fig. E5A-C) to a degree that matched the prior experiments using CC10-Cre mice. Greater, but still incomplete, reduction in AHR was observed when only CCSP-Cre ${ }^{+/-}$mice with low residual GCM were analyzed (Fig. E5D) as was observed in our studies with CC10-Cre mice (Fig. 1). Because the CCSP-Cre strain performed very similarly to the CC10-Cre strain, the CCSP-Cre stock was bred to IL-4Ra ${ }^{\text {flox/flox }}$ mice for future use, while $\mathrm{CC} 10-\mathrm{Cre}^{+}$mice were used for breeding and experimentation in the following figures.

We then compared the AHR produced by exogenous IL-13 to the AHR of AAD produced by administering $16 \mu \mathrm{g}$ of HDM from Greer i.t. every other day 7 times to mice that were IL-4Ra ${ }^{\text {flox/- }}$ and carried at most one of the Cre-constructs. Figure 2a-c demonstrates very substantial reductions in both AHR and GCM when IL4Ra expression by respiratory epithelium is targeted by Cre, without a reduction in pulmonary eosinophilia. In contrast, Fig. $2 d-f$ shows very well-preserved AHR despite Cre-mediated targeting of SMC expression of IL-4Ra, which did not noticeably affect GCM or eosinophilia.

Finding that IL-4Ra expression by SMCs did not significantly impair AAD when ECs expressed IL-4Ra normally, we wanted to determine whether such a contribution could be more readily identified when ECs had impaired expression of IL-4Ra and explore whether results varied with the preparation of HDM extract. Consequently, we administered $16 \mu \mathrm{g}$ of homemade HDM

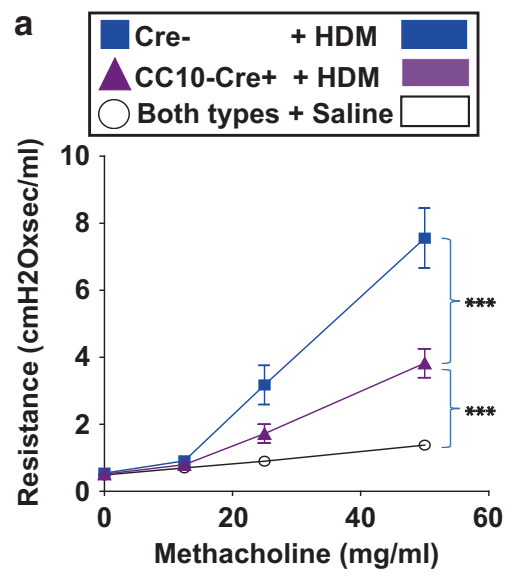

b

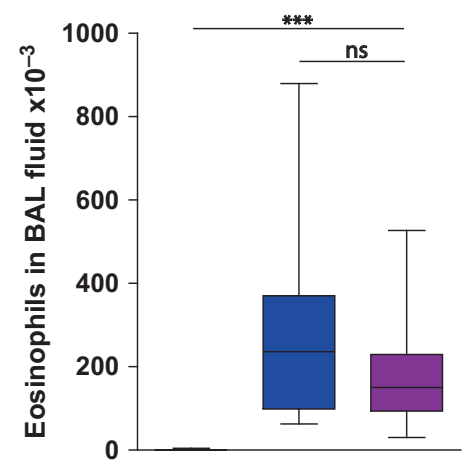

e

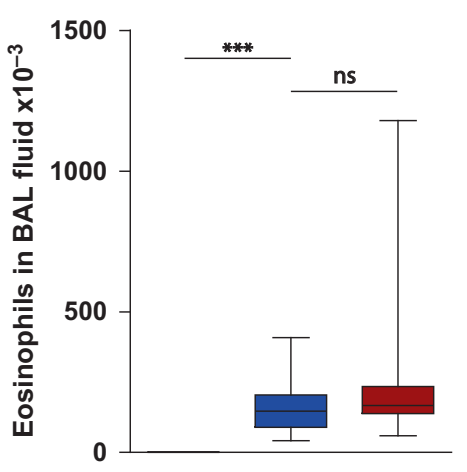

C

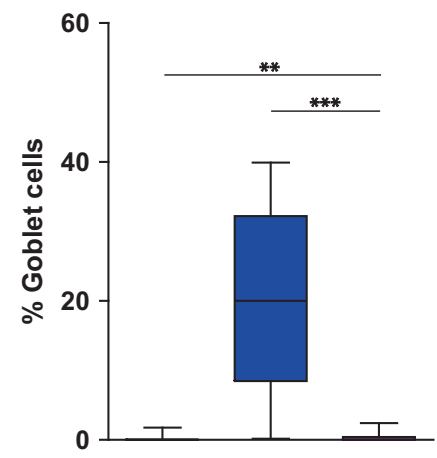

f

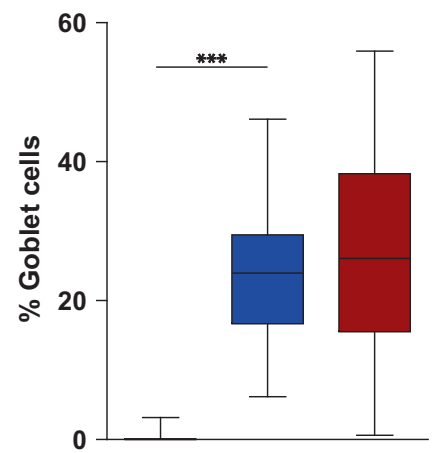

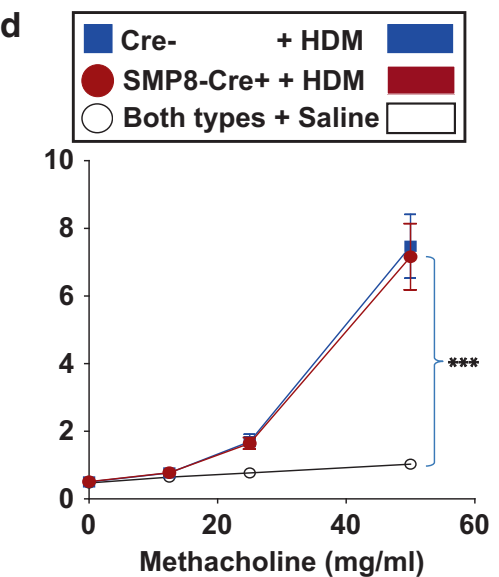

Fig. 2 Cre-mediated deletion of IL-4R $\alpha$ expression in ECs, but not SMCs, decreases AHR in house dust mite extract (HDM)-inoculated IL$4 \mathrm{R} \alpha^{\text {flox } /-}$ mice. IL-4R $\alpha^{\text {flox } /-}$ mice were treated i.t. with $16 \mu \mathrm{g}$ of HDM extract (Greer) every other day for 14 days. a Invasive measurement of AHR. b Absolute eosinophil count of BAL fluid. c Quantitation of GCM. d Invasive measurement of AHR. e Absolute eosinophil count of BAL fluid. f Quantitation of GCM. a-c The results represent 3 pooled experiments showing 17, 19, and 34 mice for the groups Cre ${ }^{-}+\mathrm{HDM}$, CC10$\mathrm{Cre}^{+}+\mathrm{HDM}$, and both genotypes+saline, respectively. d-f The results represent 5 pooled experiments showing 18, 20, and 36 mice for the groups Cre ${ }^{-}+\mathrm{HDM}$, SMP8-Cre ${ }^{+}+\mathrm{HDM}$, and both genotypes+saline, respectively. NS not significant; ${ }^{* *} p<0.01 ;{ }^{* * *} p<0.001$. 
extract i.t. every other day over a 14-day period to mice that were IL-4Ra ${ }^{\text {flox/- }}$ and carried one, both, or neither of the Cre-constructs. The resultant AHR matched the prior Greer HDM experiments, and a substantial decrement in AHR was again present in CC10$\mathrm{Cre}^{+/-}$mice but not in SMP8-Cre ${ }^{+/-}$mice (Fig. 3a). Pulmonary eosinophilia was substantial in those groups treated with HDM, irrespective of IL-4Ra expression by ECs and SMCs (Fig. 3b), while GCM depended on both HDM administration and EC IL-4Ra expression (Fig. 3C). Analogous to the IL-13-based studies, CC10-Cre ${ }^{+/-}$mice and CC10-Cre ${ }^{+/-}$SMP8-Cre ${ }^{+/-}$mice with AAD demonstrated very similar residual GCM (Fig. 3d). When comparing the AHR of the subgroups that demonstrated very good prevention of GCM, almost all AHR was attributable to EC expression of IL-4Ra (Fig. 3g), although there was an insignificant trend toward lower AHR in the group that expressed Cre in both SMCs and ECs. Again, analogous to the IL-13-based studies, eosinophilia did not consistently differ between the subgroups that demonstrated high or low residual GCM with either genotype (Fig. 3e, f).

While the AHR of CC10-Cre ${ }^{+/-} \mid \mathrm{LL}-4 \mathrm{R}^{\text {flox/- }}$ mice was substantially reduced in disease induced by exogenous IL-13, some of this reduction in the HDM-based model might have been due to reduced production of IL-13 and/or IL-4 in vivo. To address this, IL-4R flox/mice that did, or did not, carry CC10-Cre were treated i.t. with $16 \mu \mathrm{g}$ of homemade HDM every other day for 14 days and secretion of IL13 , IL-4 and interferon (IFN)- $\gamma$ were measured by In Vivo Cytokine Capture Assay (IVCCA). The substantial increase in IL-13 and IL-4 levels upon disease induction did not depend on the CC10-Cre genotype of the mouse (Fig. 3, h). Thus EC IL-4Ra expression does not appear to affect the type 2 cytokine response in AAD.

To address the potential significance of IL-4Ra heterozygosity in these experiments, we administered IL-13 to WT $\left(=\mathrm{IL}-4 \mathrm{Ra}^{+/+}\right)$ and IL-4Ra $\mathrm{Ra}^{\text {flox }}$ mice. The WT mice developed substantially greater pulmonary eosinophilia and AHR than the IL-4Ra flox/mice, although GCM appeared unaffected by IL-4Ra zygosity (Fig. $4 a-c)$. This prompted us to also compare the responses of WT and IL-4Ra ${ }^{\text {flox/- }}$ mice to HDM. Figure $4 d$ shows that the AHR of WT mice was accentuated over that of IL-4Ra ${ }^{\text {flox/- }}$ mice, while neither pulmonary eosinophilia nor GCM was affected by IL-4Ra zygosity (Fig. 4e, f). The similar GCM in IL-4Ra ${ }^{+/+}, \mathrm{IL}_{-}-4 \mathrm{Ra}^{+/-}$, and IL-4Ra ${ }^{\text {flox/- }}$ mice but increased AHR in the IL-4Ra ${ }^{+/+}$mice suggested that non-epithelial airway cells contribute considerably more to AHR in $\mathrm{IL}-4 \mathrm{Ra}^{+/+}$than in IL-4Ra ${ }^{+/-}$or IL-4Ra ${ }^{\text {flox/- }}$ mice, while cytokine levels do not depend upon a second functional IL-4Ra allele. We evaluated this hypothesis with a subsequent experiment in which cytokine levels were measured in vivo when WT and IL-4Ra ${ }^{+/-}$ mice were treated with $\mathrm{HDM}$. IL- $4 \mathrm{Ra}^{+/-}$mice actually demonstrated higher levels of IL-4 and IL-13 than WT mice (Fig. 4g). While several mechanisms might explain this finding, we favor the possibility that IL-4 and IL-13 usage (or neutralization by soluble receptors ${ }^{15}$ ) is higher in mice that have two, rather than one, functional IL-4Ra alleles.

To determine whether smooth muscle contributes more to AHR in IL-4Ra flox/flox than in IL-4Ra flox/- mice, we bred CCSP-Cre ${ }^{+/}{ }^{I L}-$ $4 \mathrm{Ra}^{\text {flox/flox }}$ mice to SMP8-Cre ${ }^{+/-} \mathrm{IL}-4 \mathrm{Ra}^{\text {flox/flox }}$ mice and treated the offspring i.t. with $16 \mu \mathrm{g}$ of Greer HDM every other day for 14 days. The AHR of HDM-inoculated IL-4Ra flox/flox mice exceeded that of IL-4Ra ${ }^{\text {flox/- }}$ mice in our prior experiments, as shown by increased sensitivity to $25 \mathrm{mg} / \mathrm{ml}$ of methacholine (compare Fig. 5a with Fig. $2 a, d)$. This increase in AHR depended substantially on the expression of IL-4Ra by both ECs and SMCs. Pulmonary eosinophilia depended on HDM treatment but was independent of IL-4Ra expression by ECs and SMCs (Fig. 5b). GCM was induced by HDM treatment and depended upon IL-4Ra expression by ECs but not by SMCs (Fig. 5c, d). Given that Cre-mediated gene disruption is typically less than complete in any cell type, the AHR of BALB/C IL-4Ra ${ }^{+/+}$mice with severe, HDM-induced AHR appears to be at least $67 \%$ attributable to EC expression of IL-4Ra alone, at least $48 \%$ attributable to SMC expression of IL-4Ra alone, and at least $83 \%$ attributable to simultaneous expression of IL-4Ra on ECs and SMCs. Indeed, when only those mice that had $<5 \%$ GCM were considered, HDM-induced AHR appeared to be $>92 \%$ attributable to simultaneous EC and SMC IL-4Ra expression (Fig. 5g). Table 1 summarizes the AHR, GCM, and pulmonary eosinophilia produced by exogenous IL-13 or HDM in all of our experiments.

\section{DISCUSSION}

AHR is the defining physiological characteristic of human asthma and animal models of this disorder.,16 The development and maintenance of AHR in most mouse models of $A A D$, which has several features in common with human asthma, completely depends on two cytokines, IL- 4 and IL-13.,5 While IL-13 is produced in higher amounts than IL-4, both bind heterodimeric receptors that share the required subunit for signal transduction, IL-4Ra. ${ }^{8,17}$ This dependence has been demonstrated in studies utilizing molecular blockade of IL-4Ra function or genetic deletion of IL-4Ra. ${ }^{10,18}$ The clinical relevance of these observations has been demonstrated by increased IL- 4 and IL-13 production in the airways of patients who have eosinophilic asthma ${ }^{19}$ and by the therapeutic success of dupilumab, a monoclonal antibody (mAb) that blocks IL-4Ra. ${ }^{20-22}$

Previous studies with mice that entirely fail to express IL-4Ra or selectively express IL-4Ra on only a single-cell type have implicated airway ECs and SMCs as important effectors in IL4Ra-dependent AHR. ${ }^{10-14}$ IL-13 administration and increased endogenous IL-13 production stimulate AHR in mice that only express IL-4Ra on smooth muscle or airway epithelium. ${ }^{10,11}$ However, in contrast to mice that globally lack IL-4Ra expression, which totally fail to develop $A H R$ and $A A D$, supraphysiological amounts of IL-13 induce AHR in mice that lack IL-4Ra on smooth muscle but express IL-4Ra on airway epithelium, and vice versa. $^{10,11}$ These observations are compatible with at least three possibilities: (1) IL-4Ra-dependent effects on either smooth muscle and airway ECs might be sufficient for IL-13 induction of AHR, regardless of IL-13 level; (2) IL-4Ra expression by both smooth muscle and airway epithelium might be more important for AHR induction when IL-13 levels are suboptimal than when supraphysiological levels of this cytokine are present; and (3) IL-4Radependent stimulation of cell types other than smooth muscle and airway epithelium, such as endothelial cells, fibroblasts, eosinophils, mast cells, macrophages, dendritic cells, and neurons, ${ }^{23-28}$ might be sufficient to induce AHR.

To distinguish among these possibilities, we studied the development of $A H R$ and other features of $A A D$ in mice using a Cre/loxp approach to selectively deplete IL-4Ra from smooth muscle, airway epithelium, or both cell types and applied this approach to mice that expressed IL-4Ra through one or two functional IL-4Ra alleles (IL-4Ra ${ }^{\text {flox/- }}$ and IL-4Ra flox/flox mice, respectively). AAD was induced in these mice by i.t. administration of either IL-13 or the clinically relevant allergen, HDM. All studies were performed in $\mathrm{BALB} / \mathrm{C}$ background mice, which reliably develop severe AHR in response to both HDM and IL-13.

In studies with IL-4Ra ${ }^{\text {flox/- }}$ mice, AHR produced by exogenous IL-13 was considerably attenuated by the absence of IL-4Ra on smooth muscle (SMP8-Cre ${ }^{+}$mice) and by the absence of IL-4Ra on airway epithelium (CC10-Cre ${ }^{+}$mice). Significantly greater suppression of HDM-induced AHR was observed when mice carried both SMP8-Cre and CC10-Cre than when mice carried only CC10-Cre, when all mice that expressed CC10-Cre were evaluated (Fig. 1a). However, this difference was not apparent when $\mathrm{CC} 10-\mathrm{Cre}^{+}$mice demonstrating considerable GCM were excluded based on the high likelihood of incomplete deletion of IL-4Ra from their epithelium by CC10-Cre (Fig. 1g).

Different results were obtained when AHR was induced by i.t. HDM, which causes less severe AHR than IL-13 at the doses used 
a

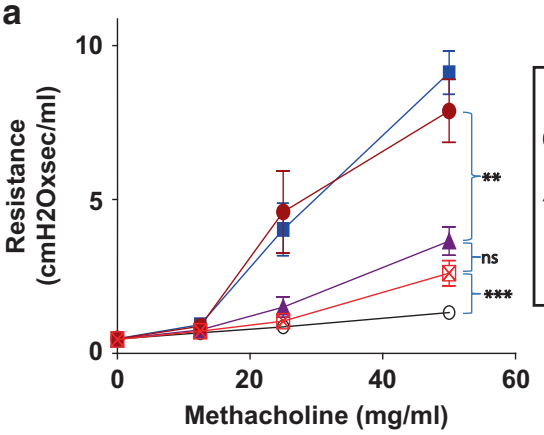

C

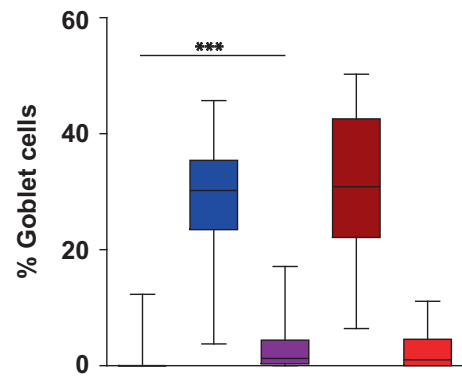

f

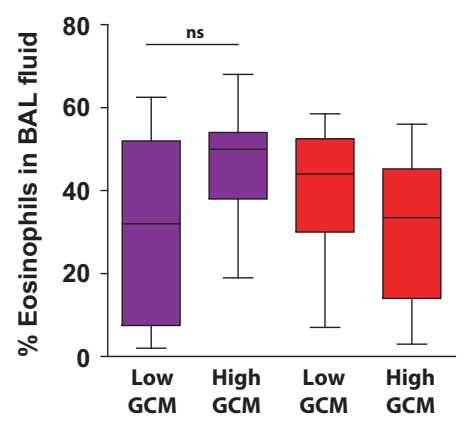

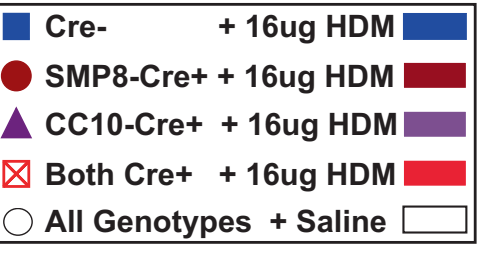

Both Cre+ + 16ug HDM
All Genotypes + Saline $\square$

\section{b}
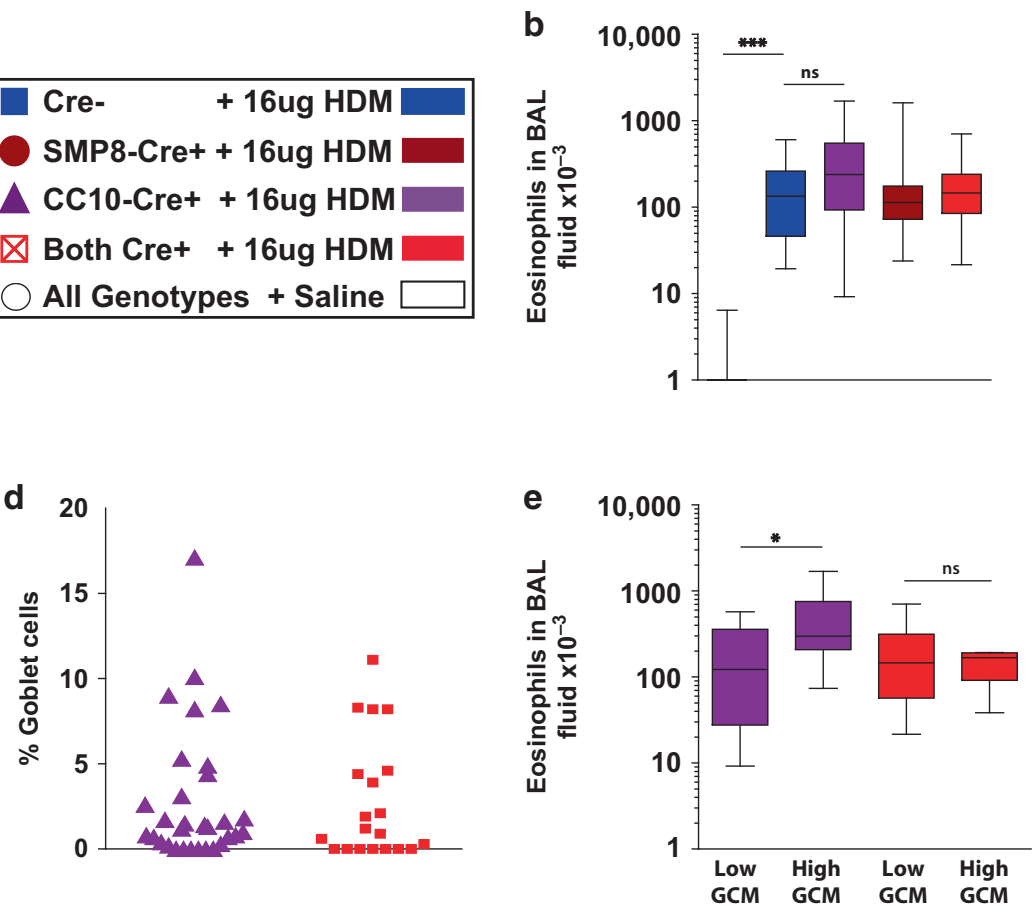

\begin{tabular}{|c|c|c|}
\hline $\begin{array}{l}\text { Cre- } \\
\text { cc10-Cre+ }\end{array}$ & $\begin{array}{l}\text { + Saline } \square \\
\text { + Saline } \square=1\end{array}$ & $\begin{array}{ll}\text { Cre- } & +16 \text { ug HDM } \\
\text { CC10-Cre+ } & +16 \text { ug HDM }\end{array}$ \\
\hline
\end{tabular}

h

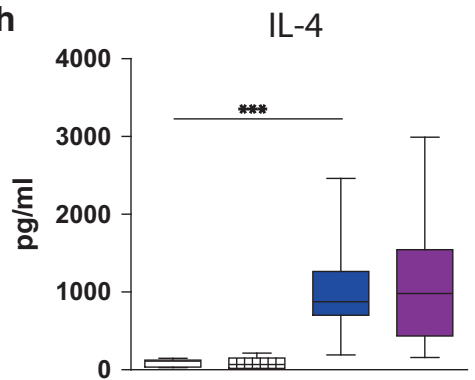

g

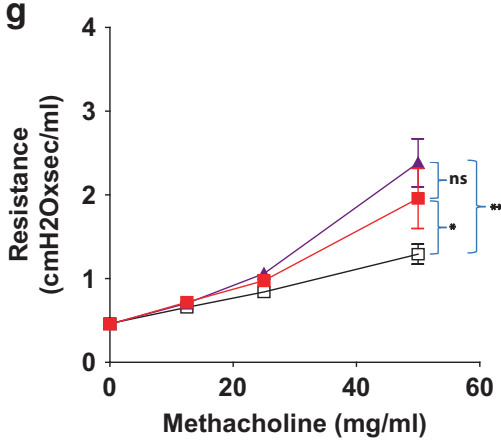

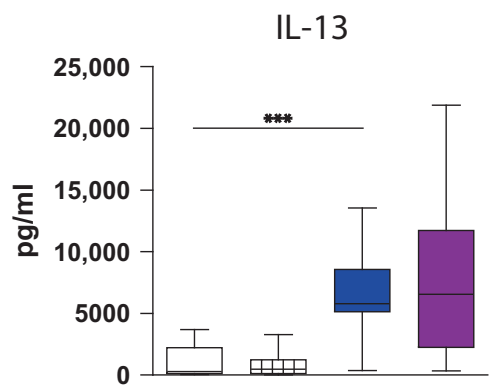

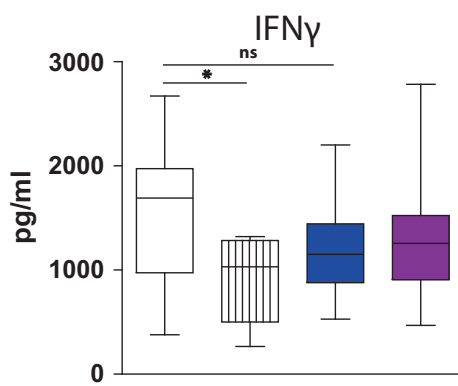

Fig. 3 SMC IL-4R $\alpha$ expression has little effect on HDM extract-induced AHR in IL-4R $\alpha^{\text {flox/- }}$ mice. IL-4R $\alpha^{\text {flox/- }}$ mice were treated i.t. with $16 \mu$ g of HDM extract (produced in our laboratory) every other day for 14 days. a Invasive measurement of AHR. b Absolute eosinophil count of BAL fluid. c Quantitation of GCM. d Distribution of residual GCM in CC10-Cre ${ }^{+}$and CC10-Cre ${ }^{+}$SMP8-Cre ${ }^{+}$mice. e Absolute eosinophil count of BAL fluid in CC10-Cre ${ }^{+}$and CC10-Cre ${ }^{+}$SMP8-Cre ${ }^{+}$mice that had high or low residual GCM. $f$ Percentage of eosinophils in BAL fluid in CC10-Cre ${ }^{+}$ mice and CC10-Cre ${ }^{+}$SMP8-Cre ${ }^{+}$that had high or low residual GCM. g AHR when CC10-Cre ${ }^{+}$and CC10-Cre ${ }^{+}$SMP8-Cre $^{+}$mice that had high residual GCM were excluded. $\mathbf{h}$ In vivo cytokine responses. For $\mathbf{a}-\mathbf{g}$, the results represent 14 pooled experiments with a-d showing: $24,19,32$, 20, and 52 mice for the groups $\mathrm{Cre}^{-}+\mathrm{HDM}, \mathrm{SMP} 8-\mathrm{Cre}^{+}+\mathrm{HDM}, \mathrm{CC} 10-\mathrm{Cre}^{+}+\mathrm{HDM}$, both $\mathrm{Cre}^{+}+\mathrm{HDM}$, and all genotypes + saline, respectively. g represents 14 and 13 mice for the groups CC10-Cre ${ }^{+}+\mathrm{HDM}$ and both $\mathrm{Cre}^{+}+\mathrm{HDM}$, respectively. $\mathbf{h}$ represents 2 pooled experiments with 9,9 , 31, and 26 mice per group: $\mathrm{Cre}^{-}+$saline, $\mathrm{CC} 10-\mathrm{Cre}^{+}+$saline, $\mathrm{Cre}^{-}+\mathrm{HDM}$, and $\mathrm{CC} 10-\mathrm{Cre}{ }^{+}+\mathrm{HDM}$, respectively. NS not significant; ${ }^{*} p<0.05$; ${ }^{* *} p=0.01 ;{ }^{* * *} p<0.001$. 


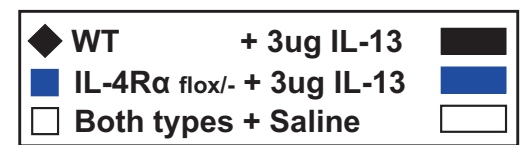

a

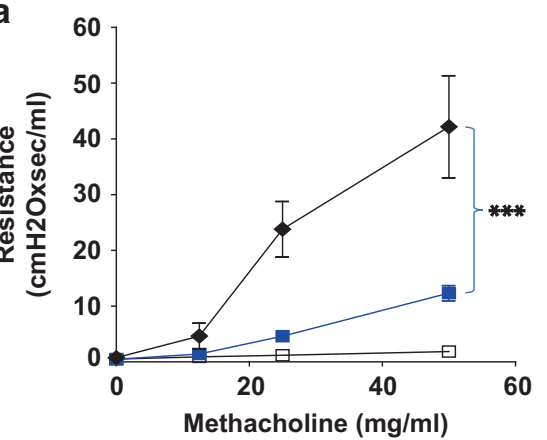

Methacholine $(\mathrm{mg} / \mathrm{ml})$ b

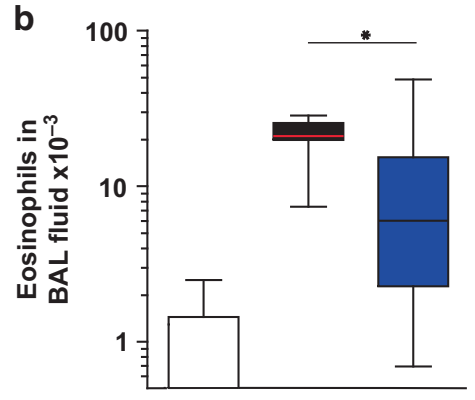

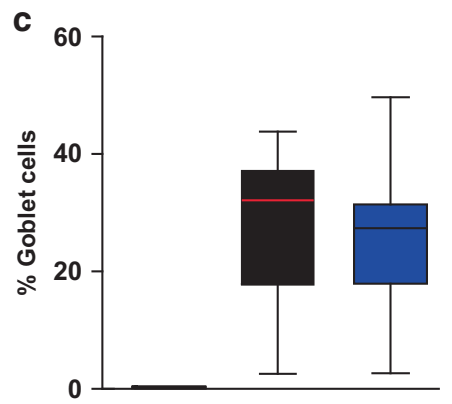

d

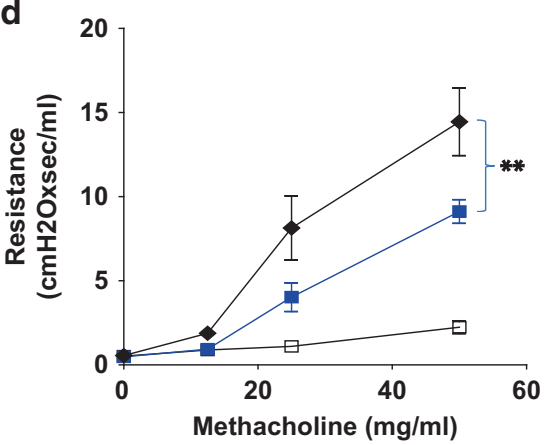

e

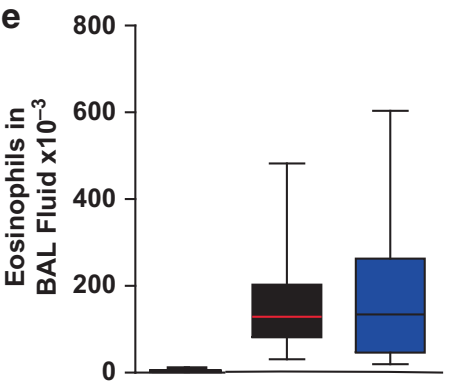

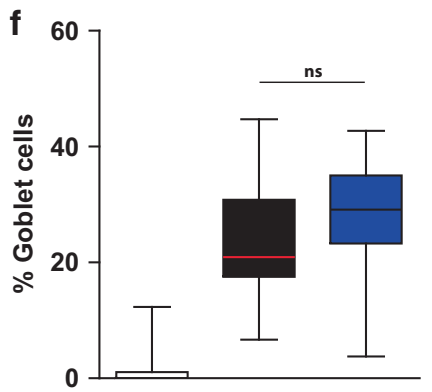

\begin{tabular}{|c|c|c|c|}
\hline $\begin{array}{l}\text { WT } \\
\text { IL-4R } \alpha+/-\end{array}$ & $\begin{array}{l}\text { + Saline } \square \\
\text { + Saline } \square\end{array}$ & $\begin{array}{l}\text { WT } \\
\text { IL-4R } \alpha+/-\end{array}$ & $\begin{array}{l}+16 u g \text { HDM } \\
+16 u g \text { HDM }\end{array}$ \\
\hline
\end{tabular}

g

IL-4

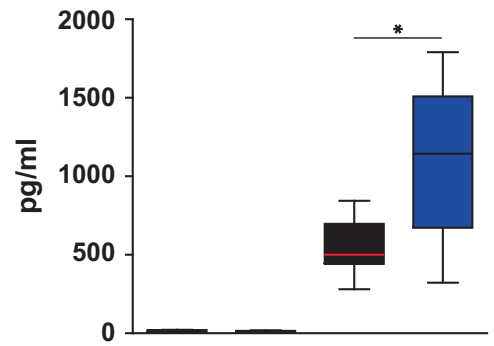

$\mathrm{IL}-13$

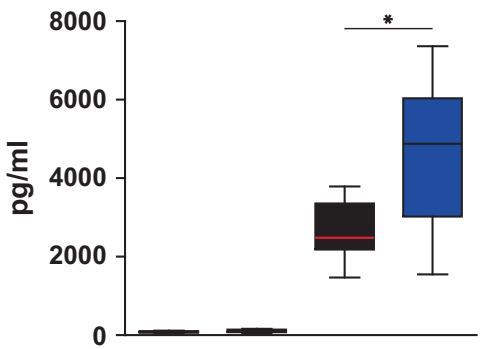

IFNY

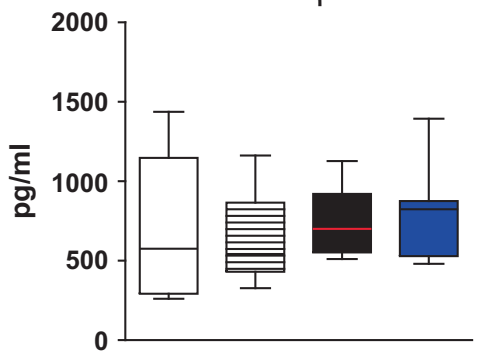

Fig. 4 A single functional IL-4R $\alpha$ allele is sufficient for induction of maximal GCM and IL-4 and IL-13 responses, but not AHR. a-c Mice were treated i.t. with $3 \mu \mathrm{g} \mathrm{IL}-13$ daily for 7 days. a Invasive measurement of AHR. b Absolute eosinophil count of BAL fluid. c Quantitation of GCM. d-g Mice were treated i.t. with $16 \mu \mathrm{g}$ HDM extract (produced in our laboratory) every other day over 14 days. d Invasive measurement of AHR. e Absolute eosinophil count of BAL fluid. $\mathbf{f}$ Quantitation of GCM. $\mathbf{g}$ Measurement of cytokine production in vivo for $\sim 24 \mathrm{~h}$ following the seventh i.t. treatment with HDM or saline. a-c 8,17 , and 18 mice for the experimental groups WT+IL-13, IL-4R $\alpha^{\text {flox/- }}+\mathrm{IL}-13$, and both genotypes+saline, respectively. d-f 17, 24, and 33 mice for the experimental groups WT+HDM, IL-4Ro flox/- $+\mathrm{HDM}$, and both genotypes+saline, respectively. g 5, 8, 7, and 8 mice for the groups WT+saline, IL-4R ${ }^{+/-}+$saline, WT+HDM, and IL-4R $\alpha^{+/-}+\mathrm{HDM}$, respectively. Because of breeding constraints, WT mice and IL-4R $\alpha^{+/-}$mice were not littermates to IL-4Ro ${ }^{\text {flox } /-}$ or to themselves. NS not significant; ${ }^{*} p<0.05 ;{ }^{* *} p<0.01 ;{ }^{* * *} p<0.001$.

(compare Figs. 1a and 3a). With HDM as the stimulus, AHR in IL$4 \mathrm{Ra}^{\text {flox/- }}$ mice was strongly suppressed by CC10-Cre, while SMP8Cre had no effect (Figs. 2a, d and 3a). The combination of CC10Cre and SMP8-Cre tended to suppress AHR induction more than CC10-Cre alone, but this tendency was not statistically significant whether all CC10-Cre-expressing mice or only those with the strongest suppression of GCM were analyzed (Fig. 3a, g).

Because IL-13 and HDM induced more severe AHR in WT and IL$4 \mathrm{Ra}^{\text {flox/flox }}$ mice than in IL-4Ra flox/- mice, it was possible that the effects of selective IL-4Ra deletion might also depend on IL-4Ra 

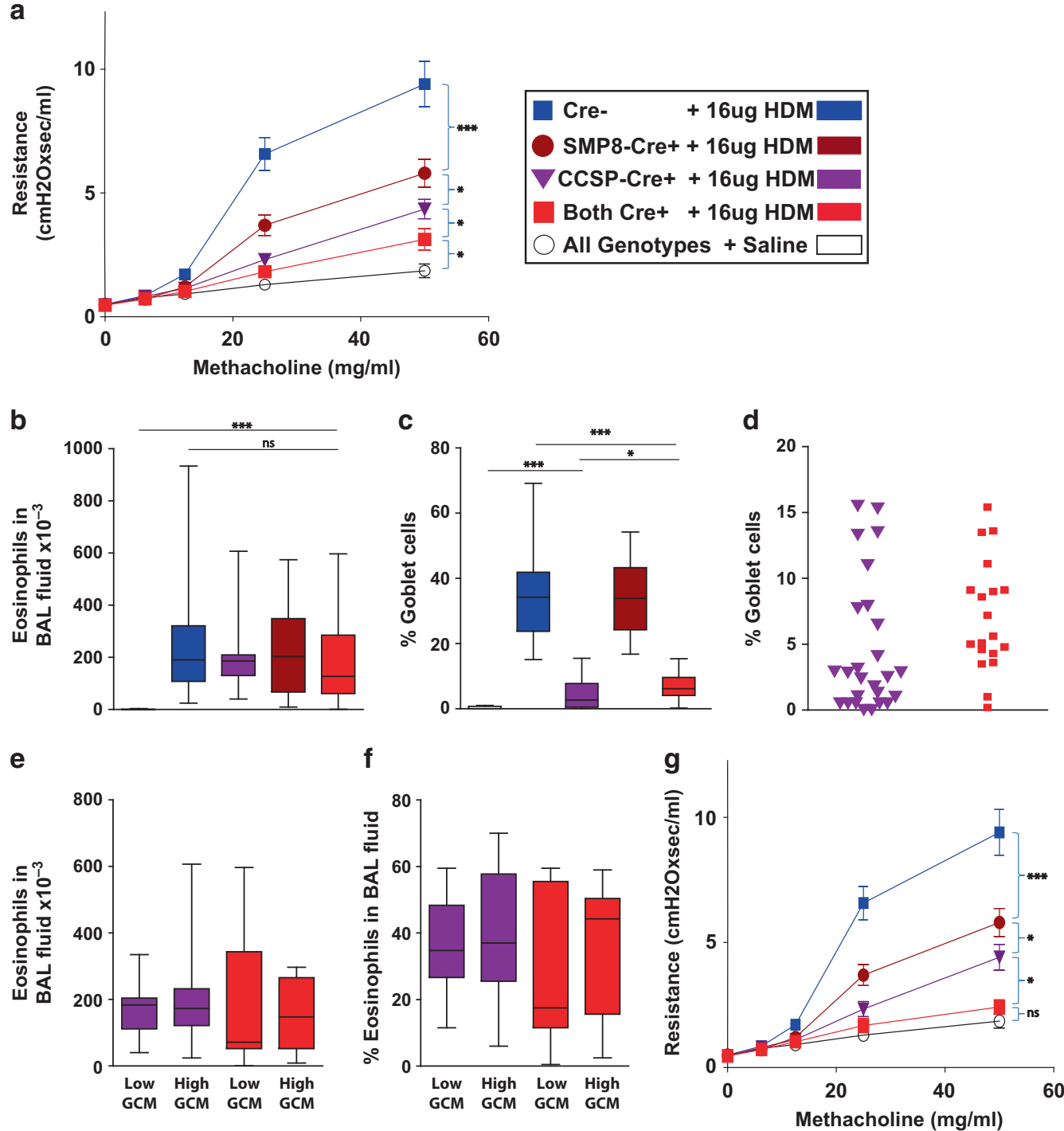

Fig. 5 Both EC and SMC IL-4R $\alpha$ expression contribute substantially to AAD AHR in IL-4R $\alpha^{\text {flox/flox }}$ mice. IL-4R $\alpha^{\text {flox/flox }}$ mice were treated i.t. with $16 \mu \mathrm{g}$ HDM extract (Greer) every other day for 14 days. a Invasive measurement of AHR. b Absolute eosinophil count of BAL fluid. c Quantitation of GCM. d Distribution of residual GCM in CCSP-Cre ${ }^{+}$and CCSP-Cre ${ }^{+}$SMP8-Cre ${ }^{+}$mice. e Absolute eosinophil counts of BAL fluid in IL-4Ra flox/flox mice that possessed the CCSP-Cre construct and had high $(>5 \%)$ or low $(<5 \%)$ percentages of residual GCM. $f$ Eosinophil percentages of BAL fluid in IL-4Ro flox/flox mice that possessed the CCSP-Cre construct and had high or low percentages of residual GCM. g Effect of CCSP-Cre and SMP8-Cre on AHR in HDM extract-immunized IL-4R $\alpha^{\text {flox/flox }}$ mice that had $<5 \%$ goblet cells in their medium-sized airways. Results represent 6 pooled experiments with a-d showing 24, 15, 28, 20, and 23 mice for the experimental groups Cre ${ }^{-}+\mathrm{HDM}$, SMP8$\mathrm{Cre}^{+}+\mathrm{HDM}$, CCSP-Cre ${ }^{+}+\mathrm{HDM}$, both $\mathrm{Cre}^{+}+\mathrm{HDM}$, and all genotypes+saline, respectively. For g, the groups CCSP-Cre ${ }^{+}+\mathrm{HDM}$ and both $\mathrm{Cre}^{+}+\mathrm{HDM}$ represent 18 and 8 mice, respectively. NS not significant; ${ }^{*} p<0.05 ;{ }^{* * *} p<0.001$.

gene dose. Indeed, in experiments performed with HDMinoculated IL-4Ra flox/flox mice, AHR was decreased by the presence of either CCSP-Cre or SMP8-Cre and further decreased by the carriage of both genetic constructs (Fig. 5a, g). Combined epithelial and smooth muscle expression of Cre decreased the maximal airway resistance induced by methacholine in HDMinoculated IL-4Ra flox/flox mice by $\sim 83 \%$, as compared to HDMinoculated IL-4Ra ${ }^{\text {flox/flox }} \mathrm{Cre}^{-}$mice and saline-inoculated mice when all mice carrying CCSP-Cre were included in our analysis. Notably, AHR appeared to be all but extinguished in HDM-treated CCSP-Cre ${ }^{+}$SMP8-Cre ${ }^{+}$mice when only those mice with $<5 \%$ GCM were included in analysis. It remains to be determined whether the remaining $A H R$ resulted from $\mathrm{LL}-4 / 1 \mathrm{~L}-13$ effects on cell types other than smooth muscle and airway epithelium or from incomplete loss of IL-4Ra expression by these two cell types. Regardless, our observations indicate that both smooth muscle and airway epithelial responsiveness to IL-4/IL-13 contribute importantly to AHR in mice with two functional IL-4Ra genes that have been immunized via the airway with a clinically relevant allergen and that the IL-4/IL-13 responsiveness of these two cell types accounts for the great majority of AHR induction by these cytokines. It remains, possible, however, that IL-4Ra expression by other cell types is necessary for AHR induced by HDM.

The likelihood that IL-4/IL-13-mediated effects on airway epithelium and smooth muscle account for most or all of the effects of these cytokines on AHR makes sense given that increases in airway resistance are caused by narrowing and occlusion of airways ${ }^{12,29,30}$. IL-4/IL-13 induction of GCM and mucus hypersecretion narrows and likely occludes airways during methacholine challenge; such narrowing and occlusion is augmented by smooth muscle contraction that is enhanced by IL-4/IL-13 activity directly on smooth muscle. 
Table 1. Summary of the results.

\begin{tabular}{|c|c|c|c|c|c|c|c|}
\hline Stimulus & $\begin{array}{l}\text { No. of functional IL- } \\
4 \mathrm{R} \alpha \text { alleles per cell } \\
\text { in smooth muscle }\end{array}$ & $\begin{array}{l}\text { No. of functional } \\
\text { IL- } 4 R \alpha \text { alleles per } \\
\text { cell in epithelium }\end{array}$ & $\begin{array}{l}\text { No. of functional } \\
\text { IL-4R } \alpha \text { alleles in all } \\
\text { other cell types }\end{array}$ & $\mathrm{AHR}$ & GC metaplasia & Eosinophilia & $\begin{array}{l}\text { Figure no. } \\
\text { in article }\end{array}$ \\
\hline Exogenous IL-13 & 1 & 1 & 1 & ++++ & ++++++++ & + & 1 \\
\hline Exogenous IL-13 & $0^{\mathrm{a}}$ & 1 & 1 & ++ & ++++++++ & + & 1 \\
\hline Exogenous IL-13 & 1 & $0^{\mathrm{a}}$ & 1 & ++ & + & + & 1 \\
\hline Exogenous IL-13 & 0 & 0 & 1 & + & + & + & 1 \\
\hline Exogenous IL-13 & 2 & 2 & 2 & ++++++++ & ++++++++ & + & 4 \\
\hline $\begin{array}{l}\text { House dust mite } \\
\text { extract }\end{array}$ & 1 & 1 & 1 & +++ & ++++++++ & ++++++++ & 2,3 \\
\hline $\begin{array}{l}\text { House dust mite } \\
\text { extract }\end{array}$ & 0 & 1 & 1 & +++ & ++++++++ & ++++++++ & 2,3 \\
\hline $\begin{array}{l}\text { House dust mite } \\
\text { extract }\end{array}$ & 1 & 0 & 1 & + & + & ++++++++ & 2,3 \\
\hline $\begin{array}{l}\text { House dust mite } \\
\text { extract }\end{array}$ & 0 & 0 & 1 & + & + & ++++++++ & 2,3 \\
\hline $\begin{array}{l}\text { House dust mite } \\
\text { extract }\end{array}$ & 2 & 2 & 2 & ++++++ & ++++++++ & ++++++++ & 4,5 \\
\hline $\begin{array}{l}\text { House dust mite } \\
\text { extract }\end{array}$ & 0 & 2 & 2 & +++ & ++++++++ & ++++++++ & 5 \\
\hline $\begin{array}{l}\text { House dust mite } \\
\text { extract }\end{array}$ & 2 & 0 & 2 & +++ & + & ++++++++ & 5 \\
\hline $\begin{array}{l}\text { House dust mite } \\
\text { extract }\end{array}$ & 0 & 0 & 2 & + & + & ++++++++ & 5 \\
\hline
\end{tabular}

a" 0 " denotes complete genetic deletion of IL-4R $\alpha$ in the great majority of the cells targeted by Cre, rather than complete genetic deletion in every Cretargeted cell

However, our observations also suggest that there are quantitative differences in AHR induction by IL-4/IL-13 effects on smooth muscle vs. airway epithelium. IL-4/IL-13 effects on airway epithelium contributed to AHR under all conditions tested, while their effects on smooth muscle were only observed in mice treated with HDM when two functional IL-4Ra alleles were present and in mice treated with supraphysiologic amounts of exogenous IL-13 when a single functional IL-4Ra allele was present. Because of this differential effect on smooth muscle and epithelium, it seems likely that greater IL-4Ra stimulation is required for smooth muscle than for airway epithelium to induce a physiologically significant effect on AHR. This is consistent with our previous observations that IL-4 and IL-13 have a much stronger effect on EC than smooth muscle gene expression. ${ }^{10}$

Experiments of the types that we have performed can be subject to artifacts; we have exerted considerable effort to investigate such possibilities. The concern that carriage of Crecontaining constructs might inhibit EC and SMC function nonspecifically was ruled out by comparing $\mathrm{AHR}$ in $\mathrm{Cre}^{-}$and $\mathrm{Cre}^{+}$ mice that had WT rather than floxed IL-4Ra genes. The concern that IL-4Ra deletion on airway ECs might be incomplete was evaluated by counting airway GCs, inasmuch as GC metaplasia is driven by IL-4/IL-13 in our model, and mice with near-complete suppression of GC metaplasia were evaluated separately, when possible. Fortunately, depletion of IL-4Ra from SMCs was likely more extensive than in ECs in our experiments. Previously ${ }^{10}$, we found that SMP8-Cre was highly effective at deleting IL-4Ra from $\mathrm{SMCs}$ in IL-4Ra ${ }^{\text {flox/- }}$ mice. However, because efficacy was not confirmed in the current experiments, we cannot completely eliminate the possibility that some of the residual AHR seen in our experiments might be due to SMC expression of IL-4Ra.

The concern that near-complete suppression of GC metaplasia might merely reflect decreased IL-4/IL-13 stimulation was excluded by evaluating airway eosinophilia, which did not correlate with the percentage of airway GCs in $\mathrm{CC} 10-\mathrm{Cre}^{+} \mathrm{IL}_{-}$
$4 \mathrm{Ra}^{\text {flox/- }}$ or IL-4Ra $\mathrm{flox}^{\text {flox }}$ mice. An additional concern, that IL-4Ra deletion from the airway epithelium might affect IL-4 and IL-13 levels, was negated by our measurement of these levels by IVCCA (Fig. 3h), showing higher levels of these cytokines in IL-4Ra flox/mice compared to WT mice (Fig. 4g). The finding that IL-4Ra heterozygosity increased levels of IL- 4 and IL-13 was unexpected. While several mechanisms for this are certainly possible and not mutually exclusive, an increased absorption of these cytokines in the WT mice because of higher expression of cytokine receptors has a good chance of contributing to this phenomenon. However, because we measured IL-4 and IL-13 systemically, we cannot exclude the possibility that a selective decrease in expression of IL4Ra on airway smooth muscle or epithelium selectively increases local concentrations of IL-4/IL-13 by decreasing cellular receptor absorption of these cytokines. These putative increased IL-4/IL-13 concentrations could then stimulate the remaining IL-4Ra-expressing cell types to a greater extent. If so, this compensatory effect could lead to underestimation of the effects of IL-4Ra deletion from a single-cell type.

There are, however, some remaining limitations of our study. As noted above, neither CC10-Cre nor CCSP-Cre reliably and completely deleted IL-4Ra from all airway ECs, as judged by residual GC metaplasia. This may have led us to underestimate the importance of GC metaplasia and other possible effects of IL-4/IL13 on airway epithelium in the pathogenesis of AHR. Second, SMP8 is not completely specific for SMCs but is also expressed by myofibroblasts 9 . Consequently, our data are consistent with the possibility that IL-4Ra expression by this cell type contributes to AHR. Most importantly, there are considerable differences between murine and human airway anatomy, including the presence of submucosal mucus glands and a substantial layer of smooth muscle in humans, as well as obvious differences in lung size and the number of divisions of bronchioles. ${ }^{2}$ Although these differences may well affect the relative quantitative importance of smooth muscle vs. airway epithelial responsiveness to IL-4/IL-13 in 
AHR pathogenesis, it seems unlikely that the combined importance of these two cell types will differ substantially between the species.

The growing use of therapies that target IL-4Ra has increased the importance of identifying the cell types that are most involved in IL-4/IL-13 contributions to immune-mediated disease. Although IL-4Ra signaling drives allergic disorders, it also protects against multicellular parasites (arthropods and worms), contributes to wound healing, and may protect against immunologic disorders mediated predominantly by non-type 2 T cells. ${ }^{31-41}$ Consequently, the safety of targeting of IL-4Ra for therapeutic means would be optimal when such therapy is specific to the organ and/or cell types that manifest disease. Because our observations demonstrate that smooth muscle and airway epithelium mediate the great majority, if not all, AHR in experimental allergic asthma and do so through expression of IL-4Ra, future asthma therapeutics might achieve an optimal risk/benefit ratio by targeting IL-4Ra expression on just these two cell types.

\section{METHODS}

Mice

Both male and female mice on the BALB/c background were used at 7-10 weeks of age in all experiments. Littermates served as controls in all experiments except where noted. IL-4Ra ${ }^{-1-}$ mice $^{42}$ and IL-4Ra flox/flox mice ${ }^{43}$ were originally provided by Frank Brombacher and bred in our animal facility. Mice carrying either a club cell $10 \mathrm{kDa}$ protein-Cre (CC10-Cre) construct ${ }^{44}$ or a-smooth muscle actin-Cre (SMP8-Cre) construct ${ }^{10}$ were provided on the C57BL/6 background by Steven Shapiro and James Fagin, respectively, and were each backcrossed $>10$ generations onto the $B A L B / c$ background. Club cell secretory protein-Cre (CCSP$(\mathrm{Cre})^{+1-} 45$ mice were backcrossed onto BALB/c and provided by Andrew Lindsley. All three of these constitutively active Cre constructs were then crossed onto the IL-4Ra ${ }^{-1-}$ background. In addition, the SMP8-Cre and CCSP-Cre constructs were crossed onto the IL-4Ra flox/flox background. For experiments on the IL$4 \mathrm{Ra}^{\text {flox/-}}$ background, CC10-Cre ${ }^{+/-} \mathrm{SMP} 8-\mathrm{Cre}^{+/-} \mathrm{IL}_{-}-4 \mathrm{Ra}^{-/-}$mice, $\mathrm{CC} 10-\mathrm{Cre}{ }^{+/-} \mathrm{IL}-4 \mathrm{Ra}^{-1-}$ mice, and SMP8-Cre ${ }^{+/-} \mathrm{IL}-4 \mathrm{Ra}^{-1-}$ mice were bred to IL-4Ra $a^{\text {flox/flox }}$ mice. For experiments on the IL$4 \mathrm{Ra}^{\text {flox/flox }}$ background, CCSP-Cre ${ }^{+-} \mathrm{IL}-4 \mathrm{Ra}^{\text {flox/flox }}$ mice were bred to SMP8-Cre ${ }^{+/}-\mathrm{IL}-4 \mathrm{Ra}^{\text {flox/flox }}$ mice. The PCR primers for genotyping mice specifically for the SMP8-Cre construct were: GCC TGT GAC ACT CCC GCT and CCA GGC TAA GTG CCT TCT CTA CA, and for the CC10-Cre and CCSP-Cre constructs: GTG CAA TाT CTT GAG TGG AGG ACA AT and TTC TTG CGA ACC TCA TCA CTC. Animals were bred and used in an AAALAC-approved specific pathogen-free environment using barrier isolation with protocols approved by the Cincinnati Children's Hospital Medical Center's (CCHMC) Institutional Animal Care and Use Committee, allowed access to food and water ad libitum, and monitored daily by the veterinary staff for health and well-being. All experimentation was performed in a manner to conscientiously minimize stress and suffering. Mice were sacrificed through intraperitoneal injection of pentobarbital and xylazine.

\section{Reagents}

Lyophilized HDM extract from Greer (Lenoir, NC), XPB70D3A25, was resuspended in sterile saline and stored at $-80^{\circ} \mathrm{C}$. We also prepared an HDM extract from whole Dermatophagoides pteronyssinus mites ( $2.04 \mathrm{~g}$, ALK-abello Source Materials Inc. (Post Falls, ID), lot\# 10-1289 and 5.03 g Greer Source Materials (Lenoir, NC), RMB82F, lot\# 166421) by pulverizing them in phosphate-buffered saline in $50 \mathrm{ml}$ conical tubes for 5 or $10 \mathrm{~min}$ using a tissue homogenizer (TissueMiser, FisherScientific) at maximum speed while on ice. Homogenate was progressively centrifuged up to $40 \mathrm{~K} \mathrm{rpm}$, and the supernatant was passed through $40-\mu \mathrm{m}$ pore strainer, brought to a $\mathrm{pH}$ of 7 , dialyzed against normal saline using a MWCO 6000-8000 membrane (Spectra Por 1, FisherScientific), filtered through a $0.45-\mu \mathrm{m}$ pore membrane by syringe, and its protein content quantitated by Bradford/Coomassie blue. Lyophilized IL-13, from PeproTech (Rocky Hill, NJ), 210-13, was resuspended in molecular-grade water and either left at room temperature for a few minutes before storing at $-80^{\circ} \mathrm{C}$ (Lot 1) or left at $4{ }^{\circ} \mathrm{C}$ for 1 week before storing at $-80^{\circ} \mathrm{C}$ (Lot 2).

Induction of airway disease

For HDM-based experiments, $16 \mu \mathrm{g}$ of HDM protein were administered i.t. in $40 \mu \mathrm{l}$ every other day for 7 treatments (Fig. E1). For IL-13-based experiments, 2 or $3 \mu \mathrm{g}$ IL-13 were administered i.t. in $40 \mu$ ldaily for 7 treatments (Fig. E2).

Determination of airway responsiveness to $\beta$-methacholine Barometric plethysmography was performed as described in some experiments ${ }^{46}$, being measured 1 day after the last treatment with HDM or approximately $8 \mathrm{~h}$ after the last treatment of IL-13. Owing to inherent imprecision and variability, this technique was abandoned and results were not reported. Invasive measurement of airway resistance was performed as described by forced oscillation using the flexiVent system (Scireq, Montreal, Canada) and measured 2 days after the last treatment with HDM or 1 day after the last treatment with IL-13. ${ }^{46}$

Bronchoalveolar lavage (BAL) and quantitation of BAL cells This was performed as described. ${ }^{47}$

Goblet cell enumeration

Periodic acid-Schiff (PAS)-stained histologic slides were prepared by the CCHMC research pathology core. ECs of all medium-sized airways in one lung section per mouse were counted in a blinded fashion and the percentage of goblet cells was calculated. Central airways were also examined for their degree of GCM. Mice were considered to have good prevention of GCM if $<2 \%$ of the cells in medium-sized airways were $\mathrm{PAS}^{+}$and central airways lacked large patches of $\mathrm{PAS}^{+}$cells.

Measurement of IL-4, IL-13, and IFN- $\gamma$ production in vivo This was achieved using the IVCCA as previously described. ${ }^{48}$ Briefly, biotin-labeled anti-cytokine IgG mAbs specific for IL-4, IL-13, and/or IFN- $\gamma$ were injected intravenously a few minutes before the last i.t. treatment with HDM, these mAbs bound the cytokines of interest with high affinity at an epitope that is required for cytokine binding to their respective cytokine receptors, blood was obtained $\sim 24 \mathrm{~h}$ after injection, and serum cytokine-lgG complexes were quantitated by enzyme-linked immunosorbent assay (Fig. E3).

\section{Statistics}

Shapiro-Wilk test was used to determine whether data sets were normally distributed, which was generally not the case. For significance testing, non-parametric Kruskal-Wallis test was used for multiple group comparisons, non-parametric Mann-Whitney $U$ test was used to compare two groups, and a two-way analysis of variance was used to analyze methacholine challenges. "Box and whiskers" plots depict the second and third quartiles of data within boxes, which are additionally marked with the median value and depict the highest and lowest values with bars. A $p$ value $\leq 0.05$ was considered significant.

\section{ACKNOWLEDGEMENTS}

We thank Frank Brombacher, Steven Shapiro, and James Fagin for sharing their mice. This research was funded by NIH R01 HL097360 (to F.D.F.), NIH/NIAID T32 Al060515 (to C.G.M.), and a University of Cincinnati Department of Internal Medicine Fellow to Faculty Award (to C.G.M.) 


\section{AUTHOR CONTRIBUTIONS}

C.G.M. designed and executed all experiments, evaluated and analyzed the data, and wrote the manuscript. C.P. bred and genotyped most of the mice. F.D.F. conceived the study, evaluated the data, and revised the manuscript.

\section{ADDITIONAL INFORMATION}

The online version of this article (https://doi.org/10.1038/s41385-019-0232-7) contains supplementary material, which is available to authorized users.

Competing interests: The authors declare no competing interests.

Publisher's note Springer Nature remains neutral with regard to jurisdictional claims in published maps and institutional affiliations.

\section{REFERENCES}

1. Steel, M. D. \& Holgate, S. T. in Samter's Immunologic Diseases 6th edn (eds Austen, K. F., Frank, M. M., Atkinson, J. P. \& Cantor, H.) 836-864 (Lippincott Williams \& Wilkins, Philadelphia, 2001).

2. Finkelman, F. D. \& Wills-Karp, M. Usefulness and optimization of mouse models of allergic airway disease. J. Allergy Clin. Immunol. 121, 603-606 (2008).

3. Wills-Karp, M. et al. Interleukin-13: central mediator of allergic asthma. Science 282, 2258-2261 (1998).

4. Perkins, C., Wills-Karp, M. \& Finkelman, F. D. IL-4 induces IL-13-independent allergic airway inflammation. J. Allergy Clin. Immunol. 118, 410-419 (2006).

5. Grunig, G. et al. Requirement for IL-13 independently of IL-4 in experimental asthma. Science 282, 2261-2263 (1998).

6. Le Gros, G., Ben-Sasson, S. Z., Seder, R., Finkelman, F. D. \& Paul, W. E. Generation of interleukin 4 (IL-4)-producing cells in vivo and in vitro: IL-2 and IL-4 are required for in vitro generation of IL-4-producing cells. J. Exp. Med. 172, 921-929 (1990).

7. Coffman, R. L. et al. B cell stimulatory factor- 1 enhances the $\lg E$ response of lipopolysaccharide-activated B cells. J. Immunol. 136, 4538-4541 (1986).

8. Zurawski, S. M. et al. The primary binding subunit of the human interleukin-4 receptor is also a component of the interleukin-13 receptor. J. Biol. Chem. 270, 13869-13878 (1995).

9. Hashimoto, S., Gon, Y., Takeshita, I., Maruoka, S. \& Horie, T. I. L.-4 and IL-13 induce myofibroblastic phenotype of human lung fibroblasts through c-Jun $\mathrm{NH} 2$-terminal kinase-dependent pathway. J. Allergy Clin. Immunol. 107, 1001-1008 (2001).

10. Perkins, C. et al. Selective stimulation of IL-4 receptor on smooth muscle induces airway hyperresponsiveness in mice. J. Exp. Med. 208, 853-867 (2011).

11. Kuperman, D. A. et al. Direct effects of interleukin-13 on epithelial cells cause airway hyperreactivity and mucus overproduction in asthma. Nat. Med. 8, 885-889 (2002)

12. Wagers, S., Lundblad, L. K., Ekman, M., Irvin, C. G. \& Bates, J. H. The allergic mouse model of asthma: normal smooth muscle in an abnormal lung? J. Appl. Physiol. (1985) 96, 2019-2027 (2004).

13. Kuperman, D. A. et al. IL-4 receptor signaling in Clara cells is required for allergeninduced mucus production. J. Immunol. 175, 3746-3752 (2005).

14. Kirstein, F. et al. Expression of IL-4 receptor alpha on smooth muscle cells is not necessary for development of experimental allergic asthma. J. Allergy Clin. Immunol. 126, 347-354 (2010).

15. Khodoun, M. et al. Differences in expression, affinity, and function of soluble (s)IL4Ralpha and sIL-13Ralpha2 suggest opposite effects on allergic responses. J. Immunol. 179, 6429-6438 (2007).

16. Lewkowich, I. P. \& Wills-Karp, M. in Middleton's Allergy: Principles and Practice 7th edn (eds Busse, W., Bochner, B., Holgate, S., Estelle Simons, F. \& Lemanske, R.) Ch. 28 (Elsevier, London, 2008)

17. Zurawski, S. M., Vega, F. Jr., Huyghe, B. \& Zurawski, G. Receptors for interleukin-13 and interleukin- 4 are complex and share a novel component that functions in signal transduction. EMBO J. 12, 2663-2670 (1993).

18. Tomkinson, A. et al. A murine IL-4 receptor antagonist that inhibits IL-4- and IL13-induced responses prevents antigen-induced airway eosinophilia and airway hyperresponsiveness. J. Immunol. 166, 5792-5800 (2001).

19. Huang, S. K. et al. IL-13 expression at the sites of allergen challenge in patients with asthma. J. Immunol. 155, 2688-2694 (1995).

20. Wenzel, S. et al. Dupilumab in persistent asthma with elevated eosinophil levels. N. Engl. J. Med. 368, 2455-2466 (2013).
21. Castro, M. et al. Dupilumab efficacy and safety in moderate-to-severe uncontrolled asthma. N. Engl. J. Med. 378, 2486-2496 (2018).

22. Rabe, K. F. et al. Efficacy and safety of dupilumab in glucocorticoid-dependent severe asthma. N. Engl. J. Med. 378, 2475-2485 (2018).

23. Barnes, J. C. et al. CXCR3 requirement for the interleukin-13-mediated upregulation of interleukin-13ralpha2 in pulmonary fibroblasts. Am. J. Respir. Cell Mol. Biol. 53, 217-225 (2015)

24. Jenkins, S. J. et al. Local macrophage proliferation, rather than recruitment from the blood, is a signature of TH2 inflammation. Science 332, 1284-1288 (2011).

25. Lopez-Bravo, M. et al. IL-4 blocks TH1-polarizing/inflammatory cytokine gene expression during monocyte-derived dendritic cell differentiation through histone hypoacetylation. J. Allergy Clin. Immunol. 132, 1409-1419 (2013).

26. McLeod, J. J., Baker, B. \& Ryan, J. J. Mast cell production and response to IL-4 and IL-13. Cytokine 75, 57-61 (2015).

27. Oetjen, L. K. et al. Sensory neurons co-opt classical immune signaling pathways to mediate chronic itch. Cell 171, 217.e13-228.e13 (2017).

28. Yamani, A. et al. The vascular endothelial specific IL-4 receptor alpha-ABL1 kinase signaling axis regulates the severity of IgE-mediated anaphylactic reactions. $J$. Allergy Clin. Immunol. 142, 1159.e5-1172.e5 (2018).

29. Lundblad, L. K. et al. Airway hyperresponsiveness in allergically inflamed mice: the role of airway closure. Am. J. Respir. Crit. Care Med. 175, 768-774 (2007).

30. Chapman, D. G. \& Irvin, C. G. Mechanisms of airway hyper-responsiveness in asthma: the past, present and yet to come. Clin. Exp. Allergy 45, 706-719 (2015).

31. Shen, E., Xie, K., Jwo, K., Smith, J. \& Mosaed, S. Dupilumab-induced follicular conjunctivitis. Ocul. Immunol. Inflamm. 27, 1339-1341 (2019).

32. Tracey, E. H. et al. Erythrodermic presentation of psoriasis in a patient treated with dupilumab. JAAD Case Rep. 4, 708-710 (2018).

33. Sevray, M., Dupre, D., Misery, L. \& Abasq-Thomas, C. Hair regrowth and dissemination of molluscum contagiosum: two unexpected effects with dupilumab. J. Eur. Acad. Dermatol. Venereol. 33, e296-e298 (2019).

34. Safa, G. \& Paumier, V. Psoriasis induced by dupilumab therapy. Clin. Exp. Dermatol. 44, e49-e50 (2019).

35. Yazdanyar, S. \& Jemec, G. B. E. Alopecia areata after treatment with dupilumab. Dermatitis 30, 175-176 (2019).

36. Maloney, N. J., Worswick, S. \& Cheng, K. Development of alopecia in patients treated with dupilumab. Dermatol. Ther. 32, e12869 (2019).

37. Flanagan, K., Sperling, L. \& Lin, J. Drug-induced alopecia after dupilumab therapy. JAAD Case Rep. 5, 54-56 (2019).

38. Seno, $\mathrm{H}$. et al. Efficient colonic mucosal wound repair requires Trem2 signaling. Proc. Natl Acad. Sci. USA 106, 256-261 (2009).

39. Allen, J. E. \& Wynn, T. A. Evolution of Th2 immunity: a rapid repair response to tissue destructive pathogens. PLoS Pathog. 7, e1002003 (2011).

40. Urban, J. F. Jr. et al. Stat6 signaling promotes protective immunity against Trichinella spiralis through a mast cell- and T cell-dependent mechanism. J. Immunol. 164, 2046-2052 (2000).

41. Herbert, D. R., Orekov, T., Perkins, C., Rothenberg, M. E. \& Finkelman, F. D. IL-4R alpha expression by bone marrow-derived cells is necessary and sufficient for host protection against acute schistosomiasis. J. Immunol. 180, 4948-4955 (2008).

42. Mohrs, M. et al. Differences between IL-4- and IL-4 receptor alpha-deficient mice in chronic leishmaniasis reveal a protective role for IL-13 receptor signaling. J. Immunol. 162, 7302-7308 (1999).

43. Herbert, D. R. et al. Alternative macrophage activation is essential for survival during schistosomiasis and downmodulates $T$ helper 1 responses and immunopathology. Immunity 20, 623-635 (2004).

44. Ji, $\mathrm{H}$. et al. K-ras activation generates an inflammatory response in lung tumors. Oncogene 25, 2105-2112 (2006).

45. Zandvakili, I., Davis, A. K., Hu, G. \& Zheng, Y. Loss of RhoA exacerbates, rather than dampens, oncogenic K-Ras induced lung adenoma formation in mice. PLOS ONE 10, e0127923 (2015).

46. McKnight, C. G., Jude, J. A., Zhu, Z., Panettieri, R. A. Jr. \& Finkelman, F. D. House dust mite-induced allergic airway disease is independent of $\operatorname{IgE}$ and FcepsilonRlalpha. Am. J. Respir. Cell Mol. Biol. 57, 674-682 (2017).

47. McKnight, C. G. et al. NKT cells contribute to basal IL-4 production but are not required to induce experimental asthma. PLOS ONE 12, e0188221 (2017).

48. Finkelman, F., Morris, S., Orekhova, T. \& Sehy, D. The in vivo cytokine capture assay for measurement of cytokine production in the mouse. Curr. Protoc. Immunol. Chapter 6, Unit 6.28 (2003). 